Çukurova Üniversitesi Mühendislik Mimarlık Fakültesi Dergisi, 33(2), ss. 33-44, Haziran 2018

Çukurova University Journal of the Faculty of Engineering and Architecture, 33(2), pp. 33-44, June 2018

\title{
Sürdürülebilir Yapı Malzemesi Hedefiyle Demir Çelik ve Plastik Endüstrisi Atıklarının Geri Kazanımı
}

\author{
Merve TUNA KAYILI"1 ${ }^{*}$, Gülser ÇELEBi'², Abdulmecit GÜLDAŞ ${ }^{3}$ \\ ${ }^{1}$ Karabük Üniversitesi, Mimarlık Fakültesi, Mimarlı Bölümü, Karabük \\ ${ }^{2}$ Çankaya Üniversitesi, Mimarlık Fakültesi, İç Mimarlık Bölümü, Ankara \\ ${ }^{3}$ Gazi Üniversitesi, Teknoloji Fakültesi, Imalat Mühendisliği Bölümü, Ankara
}

Geliş tarihi: 13.06 .2017

Kabul tarihi: 29.06 .2018

Öz

Demir-çelik ve plastik endüstrisi ithal girdisi yüksek endüstrilerdendir. Bu endüstrilerin üretim ve ürünün kullanım sonrası evresinde çok miktarda atık meydana gelmektedir. Demir-çelik endüstrisinin üretim evresi atıklarından en problemli atık, yüksek firın baca tozu (YFBT) atığıdır. Kullanım oranını her geçen gün artıran plastikler kullanım ömrünü doldurduğunda yüksek bozunma süresinden dolayı doğada uzun yıllar atık olarak kalabilmektedir. Türkiye'de ve dünyada en fazla kullanım hacmine sahip plastik türü ise düşük yoğunluklu polietilen (LDPE)'dir. Bu atıkların geri kazanımı, çevre problemlerinin azaltılması ve ürünlerin ülke ekonomisine kazandırılması açısından önemlidir. Bu çalışmada LDPE ve YFBT ekstrüzyon yöntemiyle bir araya getirilmiş ve kompozit granül üretilmiştir. Üretilen kompozit granüller enjeksiyon yöntemiyle şekillendirilmiş, mekanik özellikleri incelenmiş ve elde edilen kompozit malzemenin yapıda zemin kaplama malzemesi olarak kullanılabileceği belirlenmiştir.

Anahtar Kelimeler: Yüksek fırın baca tozu, Atık LDPE, Kompozit, Zemin kaplama malzemesi

\section{Recovery of Wastes of Iron-Steel and Plastic Industries for Sustainable Construction Material}

\begin{abstract}
The iron-steel and plastics industries are high-end import industries. A lot of waste occurs both at the production phase and post-production phase in these industries. The most problematic waste of the production phase in the iron-steel industry is blast furnace dust (BFD) waste. The plastics that increase the usage rate day by day, can stay in the nature for many years as a waste when they fill the service life, due to the high degradation period. The most used type of plastic is low-density polyethylene (LDPE) in Turkey and in the world. It is important to recycle these wastes, to reduce environmental problems, and to save the economy of Turkey. In this study, LDPE and BFD were combined by extrusion method and composite granules were produced. The produced composite granules were shaped by injection method, their mechanical properties were investigated, and the composite material determined could be used as flooring material in construction.
\end{abstract}

Keywords: Blast furnace dust, Waste LDPE, Composite, Flooring material

*Sorumlu yazar (Corresponding author): Merve TUNA KAYILI, mervetunakayili@karabuk.edu.tr 


\section{GíRiş}

Günümüzde yüksek oluşum enerjili yapı ürünlerinin üretiminde, fosil kaynaklı üretimden kaynaklanan hava kirliliğinin yanı sıra çok miktarda atık meydana gelmektedir. Ürünlerin kullanım sürecinde sıklıkla karşılaştığımız atıklar, üretim sürecinde de bir hayli fazla olabilmektedir.

Yapı ürünü üretim sürecinde yüksek enerjili üretim yapan ve büyük oranda üretim süreci atıklarına sahip endüstrilerden biri demir çelik endüstrisidir. $\mathrm{Bu}$ endüstri, demir çelik üretimi sırasında yüksek hava kirliliği yaratımına ek olarak 1 ton çelik üretimi başına $400 \mathrm{~g}$ çeşitli katı atıklar ortaya çıkarabilmektedir [1]. Cüruf haricindeki katı atıklar yüksek firın toz ve çamurları, sinter fabrikalarının tozları, çelikhane toz ve çamurları, pota metalurji tesisleri tozları, yağlı tufaller, haddehane tufalleri ve ark ocağı tozlarıdır. $\mathrm{Bu}$ atıkları tozlar, çamurlar ve tufaller şeklinde sınıflandırmak mümkündür [2]. Demir ve çelik tesislerinde oluşan bu katı atıklar, demir ve çelik üreticileri ve çevre için büyük bir sorun teşkil etmektedir. Büyük miktarda ortaya çıkmaları, çok ince taneli olmaları ve kimyasal kompozisyonlarında istenmeyen safsızlıkların $\left(\mathrm{K}_{2} \mathrm{O}, \mathrm{Na}_{2} \mathrm{O}, \mathrm{Zn}\right.$ gibi) yüksek olması, atıkların sinter yoluyla üretime geri döndürülmesine mani olmakta ve kısıtlamaktadır [3-5]. Bu açıdan en problemli atık tozlar, yüksek firın baca tozu ve oksijen konverter tozlarıdır. Türkiye'de atık olarak çıkan yıllık baca tozu miktarı ise 375.000-425.000 ton olarak verilmektedir [2]. Bu nedenle, baca tozlarının geri kazanımı, hem depolama ve çevre problemleri açısından, hem de değer ihtiva eden metallerin geri kazanımı açısından önem arz etmektedir [6].

Üretim enerjisi yüksek bir diğer yapı ürünü ise petrol tabanlı plastiklerdir. Plastikler, ekonomiklikleri, uygulama kolaylıkları ve özelliklerinin her geçen gün geliştirilmeleri nedeniyle kullanım alanlarını ve miktarlarını giderek arttırmaktadırlar. Plastiklere olan talebin artması atık plastik miktarında da artışa yol açmaktadır. Türkiye'de ve Dünya'da en çok kullanım alanına sahip plastik tipi, çeşitli konteyner üretiminde, şişeleri yıkamada, boru üretiminde, bilgisayar parçaları için plastik çanta yapımında, laboratuvar malzemeleri şekillendirmede ve ambalajlamada yaygın olarak kullanım alanına sahip düşük yoğunluklu polietilen (LDPE)'dir [7].

Bu bağlamda çalışma kapsamında, oluşum enerjisi düşük, geri kazanılmış malzeme içeren ve geri dönüştürülebilir bir yap1 malzemesi hedefiyle demir çelik atıklarından en problemlisi olan yüksek firın baca tozu ve Türkiye'de en fazla kullanım ve dolayısıyla da atık oranına sahip atık LDPE ekstrüzyon yöntemiye bir araya getirilmiş ve kompozit granül üretilmiştir. Üretilen kompozit granüller enjeksiyon yöntemiyle şekillendirilmiş, mekanik özellikleri incelenmiş ve elde edilen kompozit malzemenin yapıda zemin kaplama malzemesi olarak kullanılabileceği belirlenmiştir [6].

\section{DEMIR ÇELÍK VE PLASTIKK ENDÜSTRİSI ATIKLARI}

Demir çelik sektörü ülkemizde her geçen yıl üretim hacmini artırmaktadır. Gelişmiş ülkelerde kişi başına demir çelik tüketimi 400-500 kg civarında iken bu rakam Türkiye'de 2015 yılı sonu itibariyle $437 \mathrm{~kg}$ düzeyindedir [8]. Türkiye'de 2011 yılında 2010 yılına göre \%17 oranında bir artış ile 34,1 milyon ton ham çelik üretimi yapılmış ve bu üretim miktarı ile Türkiye çelik üretiminde dünyadaki ilk 10 ülke içerisinde yer almıştır [9]. Bu durum Türkiye'de demir çelik sektörünün ne denli büyük olduğunu, üretilen demir çelik hacmine paralel olarak artacak olan demir çelik sektörü üretim atıklarının da habercisidir.

Demir çelik sektörü üretim atıklarının büyük miktarda ortaya çıkması, çok ince taneli olması ve kimyasal kompozisyonlarında istenmeyen safsızlıkların $\left(\mathrm{K}_{2} \mathrm{O}, \mathrm{Na}_{2} \mathrm{O}, \mathrm{Zn}\right.$ gibi) nedeniyle en problemli olanları yüksek firın baca tozu ve oksijen konverter tozlarıdır [3-5,10,11]. Türkiye'de atık olarak çıkan yıllık baca tozu miktarı ise 375.000-425.000 ton olarak verilmektedir [2]. Çizelge 1'de görülebileceği gibi sadece Karabük Kardemir Demir Çelik 
Fabrikası'nda yüksek firın baca tipine bağlı olarak 6-15 ton/gün baca tozu atığı ortaya çıkmaktadır [12].

Çizelge 1. Demir çelik üretiminde ortaya çıkan atık baca tozu miktarı [12]

\begin{tabular}{|l|l|}
\hline Yüksek Fırın Tipi & Baca Tozu Miktarı \\
\hline 1. Nolu Yüksek Fırın & $12-15$ ton/gün \\
\hline 2. Nolu Yüksek Fırın & 6 ton/gün \\
\hline 3. Nolu Yüksek Fırın & 10 ton/gün \\
\hline 4. Nolu Yüksek Fırın & 14 ton/gün \\
\hline
\end{tabular}

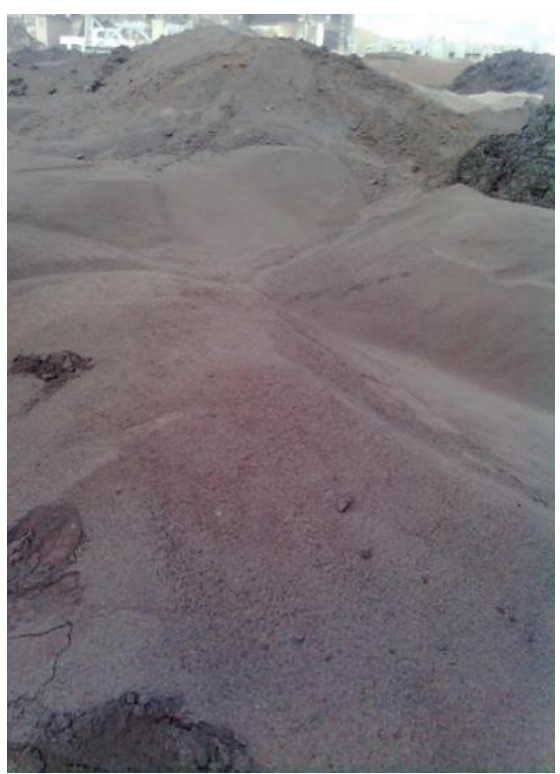

Şekil 1. Kardemir A.Ş. baca tozu atığı stoğu (2013)

Demir çelik sektörünün en önemli sorunlarından biri ağırlıklı olarak ithal girdiyle çalışması olup, elektrik ark ocaklı (EAO) kuruluşlarda hammadde olarak kullanılan hurdanın $\% 70$ civarındaki bölümünün ithal edilmesidir. 2009 yılında yaklaşık 16 milyon ton hurda ithal edilmiş ve bu ithalatın yarıdan fazlası ABD, Rusya ve AB ülkelerinden yapılmıştır. Entegre tesislerde ise, hammadde olarak kullanılan demir cevherinin yaklaşık \%60'1 ve kömürün yaklaşık \%90'1 ithal edilmektedir [2]. $\mathrm{Bu}$ durum, demir çelik üretiminde dışa bağımlılık oranımızı göstermektedir. $\mathrm{Bu}$ bağlamda, demir çelik üretimi sürecinde ortaya çıkan kimyasal yönden zengin atıkların yapıda ya da herhangi bir sektörde değerlendirilmesi ülke ekonomisi açısından çok önemlidir.

Yüksek oluşum enerjisine sahip bir diğer yapı ürünü sektörü ise petrol tabanlı olan plastiklerdir. Plastikler, dayanıklı, yalıtkan, hafif, şekil verilebilme özelliği yüksek ve esnek veya rijit olarak üretilebilmesi nedeniyle oldukça yüksek kullanım alanına sahiptir. Öyleki, 1950 yılında 1,5 milyon ton olan dünya plastik üretiminin 2014 yılında ise 312 milyon tona eriştiği tahmin edilmektedir. Dünya toplam plastik üretiminin yaklaşık \%25'i Çin ve \%53'ü Çin, ABD, Almanya, S. Arabistan ve Hindistan olmak üzere 5 ülke tarafından gerçekleştirilmektedir. Türkiye 2014 yılında eriştiği 8,2 milyon tonluk üretimi ile küresel üretimden \%2,6 pay alarak dünyada yedinci, AB'de ise Almanya'dan sonra ikinci büyük plastik üretimine sahiptir [13].

Türkiye'de plastik tüketimini yönlendiren başlıca sektörler, dünyada da olduğu gibi ambalaj ve inşaat malzemeleri sektörleridir [14]. Türkiye'nin en büyük plastik üreticisi Petro Kimya Holding'in (Petkim) 2014 verilerine göre, en çok üretim hacmi termoplastik çeşidinde gerçekleşmektedir. Termoplastiklerden ise y1lda en fazla üretim; monomer bazında 545,511 tonla etilende, polimer bazında ise 142,883 tonla düşük yoğunluklu polietilen tubulerde (LDPE-T) ve 132,757 tonla düşük yoğunluklu polietilende (LDPE) gözlenmektedir [7].

Plastiklerin günümüzün her alanında kullanılması, atık miktarının da her geçen gün kaçınılmaz olarak artması anlamına gelmektedir. Azaltma (reduce), yeniden kullanma (reuse), geri dönüştürme (recycle) ve geri kazanma (recover) temel atık azaltma yöntemleridir. Plastik atıklarının azaltılması için öncelikle kaynakta kullanımının etkin bir şekilde yapılması sağlanarak plastik girdisi azaltılabilmekte, kullanım ömrü dolanlar çeşitli işlemlerinden ardından yeniden kullanılarak ya da geri dönüştürülerek aynı ya da başka bir işlevle geri kazanılabilmektedir. Atık plastiklerin geri dönüşümüne yönelik bir sektörü de içine alan geri dönüşüm ve kompozit malzeme çalışmalarının yapılması atı sorununun çözümüne katk1 sunacaktır [6]. 


\section{KOMPOZITT MALZEME ÜRETIMI}

$\mathrm{Bu}$ bölümde kompozit malzemenin oluşturulmasında kullanılan atık malzemelerin özelliklerine ve malzeme üretim yöntemine yer verilmiştir.

\subsection{Yüksek Fırın Baca Tozu}

Kardemir Demir Çelik Fabrikası'nda 4 farklı yüksek firın bulunmaktadır. Her tip firından farklı miktarlarda baca tozu atığı oluşmaktadır. Bu firınlardan ortaya çıkan baca tozlarının kimyasal bileşenleri de, içinde üretilen hurda çeliğin kalitesine göre küçük farklılıklar gösterebilmektedir. Çizelge 1'de izleneceği üzere, günlük en fazla atık üretimine sahip ve içlerinde en yüksek çinko oksit oranına sahip yüksek firın tipi, 4 nolu yüksek firındır. Bu nedenle çalıșmada, 4 nolu yüksek firından 25.05.2015 tarihinde alınan yüksek firın baca tozu kullanılmıştır. Kardemir Kalite Metalurji ve Laboratuvarı'na gönderilen baca tozu örnekleminin kimyasal analizi ve tane boyut dağılımı Çizelge 2 ve 3 'te verilmiştir. Yapılan analizlere göre yüksek firın baca tozunun çoğunlukla demir oksitten oluştuğu ve 125 ile $500 \mu \mathrm{m}$ büyüklükte olduğu belirlenmiştir.

Çizelge 2. Baca tozu kimyasal analizi (Kardemir A.Ş. Lab.)

\begin{tabular}{|c|c|c|c|c|c|}
\hline $\mathrm{Fe}_{2} \mathrm{O}_{3}$ & $\mathrm{C}$ & $\mathrm{S}$ & $\mathrm{Al}_{2} \mathrm{O}_{3}$ & $\mathrm{SiO}_{2}$ & $\mathrm{CaO}$ \\
\hline 52,97 & 17,92 & 0,27 & 1,21 & 11,54 & 9,24 \\
\hline $\mathrm{MgO}$ & $\mathrm{Na}_{2} \mathrm{O}$ & $\mathrm{K}_{2} \mathrm{O}$ & $\mathrm{ZnO}$ & $\mathrm{MnO}$ & \\
\hline 1,30 & 0,05 & 0,28 & 0,29 & 0,84 & \\
\hline
\end{tabular}

Çizelge 3. Baca tozu tane boyut dağılımı (\%)

\begin{tabular}{|l|c|c|c|c|}
\hline Boyut & $500 \mu \mathrm{m}$ & $250 \mu \mathrm{m}$ & $125 \mu \mathrm{m}$ & $62 \mu \mathrm{m}$ \\
\hline$\%$ & 31,35 & 21,75 & 27,42 & 3,98 \\
\hline Boyut & $44 \mu \mathrm{m}$ & $34 \mu \mathrm{m}$ & $24 \mu \mathrm{m}$ & $16 \mu \mathrm{m}$ \\
\hline$\%$ & 3,06 & 5,73 & 2,37 & 0,9 \\
\hline Boyut & $13 \mu \mathrm{m}$ & $9 \mu \mathrm{m}$ & $6,4 \mu \mathrm{m}$ & $4,5 \mu \mathrm{m}$ \\
\hline$\%$ & 1,33 & 0,46 & 0,61 & 0,98 \\
\hline
\end{tabular}

\subsection{Atık LDPE}

Atık LDPE örneklemi, Ankara'nın Kahraman Kazan İlçesi'nde plastik şeffaf örtü üretimi yapan bir fabrikanın üretim sürecinde ortaya çıkan LDPE atıklarından tesadüfi olarak oluşturulmuştur. Atık LDPE ile baca tozunun özdeş olarak karışabilmesi için, baca tozu ile plastik atıklarının tane büyüklüklerinin birbirine yakın olması önemli avantajlar sağlamaktadır. $\mathrm{Bu}$ nedenle çalışma kapsamında, Çizelge 4'te verilen ticari özelliklere sahip, Şekil 2'de görülen yaklaşık $1 \mathrm{~mm}$ çapında ve kalınlığında kesimi yapılmış atık LDPE parçacıkları kullanılmıştır.

Çizelge 4. Atık polietilenin özellikleri

\begin{tabular}{|l|c|c|}
\hline Özellik & Değer & Birim \\
\hline Yoğunluk & 0,92 & $\mathrm{~g} / \mathrm{cm}^{3}$ \\
\hline Ergime sıcaklığ1 & $\sim 120$ & ${ }^{\circ} \mathrm{C}$ \\
\hline Sat1ş fiyat1 & 3 & $\mathrm{t} / \mathrm{kg}$ \\
\hline Rengi & Şeffaf/Beyaz & - \\
\hline
\end{tabular}

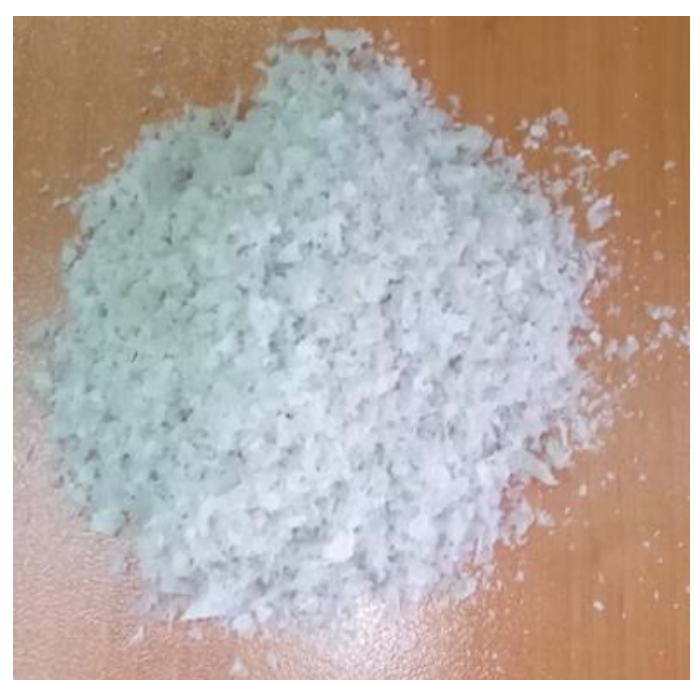

Şekil 2. Atık polietilen

\subsection{Masterbatch}

Çalışma kapsamında, kompozit malzeme üretiminde ortaya çıkan malzemenin estetik yönünü arttırmak ve boyanabilirliğini test etmek amacıyla, atık LDPE'nin \%0,1'i oranında beyaz masterbach kullanılmıştır.

\section{4. Üretim Yöntemi}

Kompozit malzeme üretiminden önce yüksek firın baca tozu ile atık LDPE ağırlıkça \%50-\%50 oranında kuru şartlarda karıştırılmış, $50{ }^{\circ} \mathrm{C}$ 'de 
1,5-2 saat fırınlanmıștır. Böylelikle üretim sonrası birçok problemlere sebep olan nem faktörünün etkisi en aza indirilmeye çalışılmıştır.

Baca tozu ve LDPE atıkları Gazi Üniversitesi Makine Mühendisliği Toz Metalurji Laboratuvarındaki çift vidalı ekstrüzyon makinesi kullanılarak $3 \mathrm{~mm}$ çapında kompozit bir tele dönüştürülmüştür. Ekstrüzyon işleminde makinede kullanılan parametreler Çizelge 5'te sunulmuştur. Tel şeklinde çıkan baca tozu katkılı LDPE, kırıcı ünitede kırılmış ve kompozit granüller elde edilmiştir. Şekil 3'te görülen $3 \mathrm{~mm}$ çapında ve 3-4 mm boyundaki granüller tekrar kurutma firınına gönderilmiş ve yine $45-50{ }^{\circ} \mathrm{C}$ 'de $1,5-2$ saat firınlanarak neminin uzaklaştırılması sağlanmıştır. $\mathrm{Bu}$ işlemlerin ardından granüller, test yöntemlerinde kullanılan standartların istediği ebatlara uygun olarak enjeksiyon makinesinde şekillendirilmiştir (Şekil 4).

Çizelge 5. Ekstrüzyon makinesi parametreleri

\begin{tabular}{|l|c|c|}
\hline Isıtma bölgesi & Sicaklik $\left({ }^{\circ} \mathrm{C}\right)$ & Mil hizı (rpm) \\
\hline I. bölge & $140-150$ & \multirow{2}{*}{$50-80$} \\
\cline { 1 - 2 } II. bölge & $165-170$ & \\
\cline { 1 - 2 } III. bölge & $190-200$ & \\
\hline
\end{tabular}

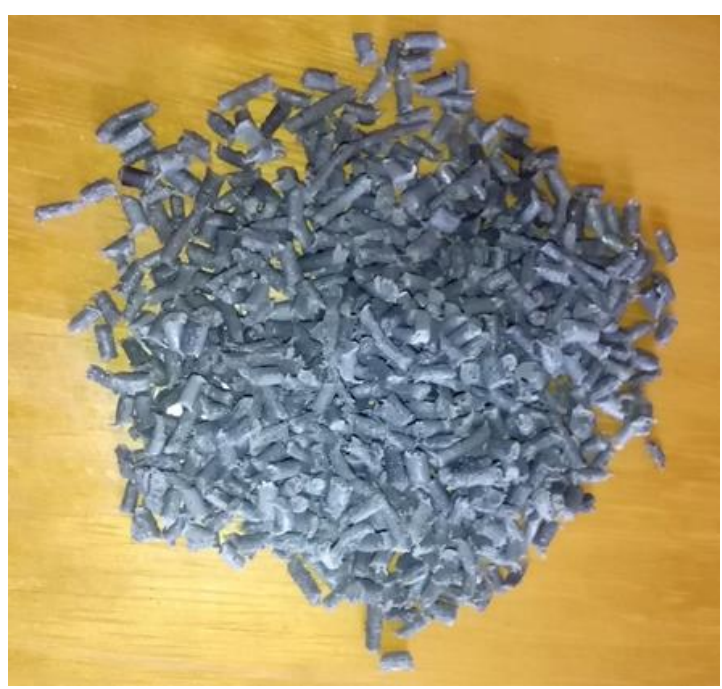

Şekil 3. \%50 baca tozu katkılı kompozit granül

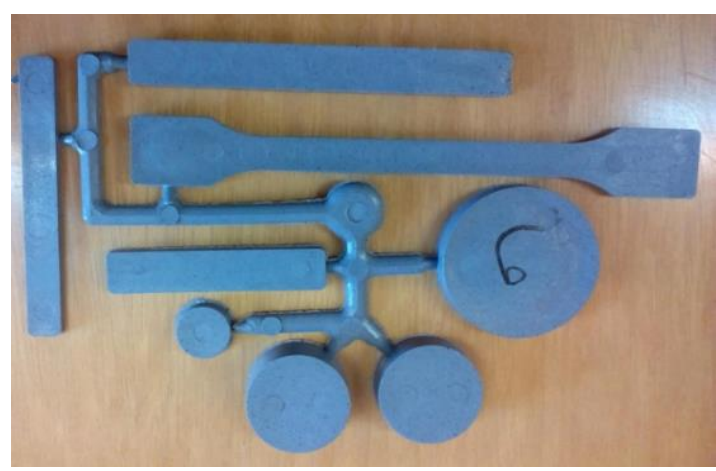

Şekil 4. Enjeksiyon yöntemiyle şekillendirilen $\% 50$ baca tozu katkılı kompozit malzeme

\subsection{Yoğunluğunun Belirlenmesi}

Tez çalışması kapsamında, numunelerin yoğunluklarının belirlenmesi amacıyla, ilk olarak $\% 50$ baca tozu katkılı numuneler, Hacettepe Üniversitesi Kimya Bölümü Laboratuvarında bulunan Memmert marka vakumlu etüvde $50{ }^{\circ} \mathrm{C}$ 'de sicaklikta 24 saat boyunca kurutma/ nem alma işlemine tabi tutulmuştur. Nemi alınan numuneler, ASTM D 792 standardı gereği yaklaşık 30 dakika boyunca oda sicaklığına gelmesi için desikatörde bekletilmiş, sonrasında havadaki ağırlıklarının belirlenmesi amacıyla $0,1 \mathrm{~g}$ hassasiyetli hassas terazide ölçülen değerleri not edilmiştir. Her tip kompozit malzemenin Eşitlik (1) yardımıyla yoğunluğu belirlenmiştir [15].

$\delta=\mathrm{Wh} / \mathrm{Vd}$

Bu eşitlikte;

$\delta$ :Yoğunluk

Wh: Malzemenin havadaki ağırlığı

Vd: Dolu hacim

\subsection{Su Emme Oranının Belirlenmesi}

Deneye başlamadan önce, $\% 50$ baca tozu katkılı kompozit numuneler, Hacettepe Üniversitesi Kimya Bölümü Laboratuvarında bulunan, Memmert marka vakumlu etüvde, $50{ }^{\circ} \mathrm{C}$ 'de sicaklıkta 24 saat boyunca kurutma/nem alma işlemine tabi tutulmuştur. Nemi alınan numuneler, yaklaşık $30 \mathrm{dk}$ boyunca oda sıcaklığına gelmesi için desikatörde bekletilmiştir. Oda sıcaklığındaki 
numunelerin, kuru ağırlıklarının belirlenmesi amaciyla $0,1 \mathrm{~g}$ hassasiyetli hassas terazide ölçülen değerleri not edilmiştir ve ardından numuneler şekilde saf su dolu beherlere atılmıştır. ASTM D 570'e uygun olarak, 2. saat, 14. gün, 28. gün, 56. gün sonrasında sudan çıkarılıp $0,1 \mathrm{~g}$ hassasiyetli hassas terazide ölçülen numunelerin, kuru ağırlık ile farkları tespit edilmiştir [16].

2 saat, 14-28-56 gün süre ile bekletilen numunelerin ağırlıkça su emme yüzdeleri Eşitlik (2) kullanılarak belirlenmiştir.

$\mathrm{Aw}=\left(\frac{\mathrm{W} 2-\mathrm{W} 1}{\mathrm{~W} 1}\right) * 100$

Bu denklemde;

Aw= Ağırlıkça su emme yüzdesi

$\mathrm{W}_{2}=$ Numunenin su emmiş ağırlığ

$\mathrm{W}_{1}=$ Numunenin kuru ağırlığ

\section{8. Çekme Dayanımının Belirlenmesi}

TS EN ISO 527-2 ve DIN EN ISO 527-5 Type 1-b standartlarına uygun olarak üretilen kompozit numunenin çekme deneyleri, Gazi Üniversitesi Teknoloji Fakültesi Metalurji ve Malzeme Mühendisliği Bölümü Laboratuvarı'nda bulunan Instron marka çok amaçlı (üniversal) test cihazında, $5 \mathrm{~mm} / \mathrm{dk}$ çekme hızı kullanılarak gerçekleştirilmiştir.

\subsection{Aşınma Dayanımının Belirlenmesi}

Kompozit numunelerin aşınma miktarlarının belirlenmesinde, Afyon Kocatepe Üniversitesi Metalurji ve Malzeme Mühendisliği Mekanik Test Laboratuvarında bulunan, ASTM G 99 Pin on Disk metoduna göre çalışan pim disk aşınma cihazı kullanılmıştır. Ayrıca aşınma deneyine başlamadan önce, aşınan malzemenin yüzey pürüzlülüğünün giderilmesi kapsamında, zımparalama/parlatma işlemi yapılması gerekmektedir. $\mathrm{Bu}$ nedenle disk numunelerin aşındırılacak yüzeyi, Gazi Üniversitesi Makine Mühendisliği Toz Metalurjisi laboratuvarında bulunan Struers marka zimparalama/parlatma cihazı ile sirasiyla $0,100,240,400,600,1000$, 1200 numara SiC zımpara kağıdına karşı sulu zımparalanmış ve kaba yüzey pürüzlülüğü giderilmeye çalışılmıştır. Zımparalama/parlatma işleminin her bir numune için tekrarlanmasının ardından, yüzey pürüzlülüğünün aşınma miktarına etkisini belirlemek amaciyla, disk numunelerin yüzey pürüzlülüğü, Gazi Üniversitesi Teknoloji Fakültesi İmalat Mühendisliği Bölümü Plastik Test Laboratuvarında bulunan Mahr marka pürüzlülük ölçüm cihazı ile tespit edilmiştir.

Yüzey pürüzlülük değeri aşınma deneyi için uygun olan disk numuneler, ASTM G 99 Pin on Disk metoduna göre çalışan pim disk aşınma cihazına yerleştirilmiştir. Belirlenen kuvvet, hiz ve yol parametrelerine göre aşındırılan numunelerin aşınma sırasındaki sürtünme kuvvetleri bilgisayar yazılımı ile tespit edilmiştir. Ayrıca numunelerin aşınma deneyi sırasında 450 ve 900 m olmak üzere iki farklı yol parametresi denenmiştir.

Malzemelerde aşınma davranışlarını ölçmek amacıyla, birçok deney düzenekleri ve aşınma direncini belirleme yöntemleri geliştirilmiştir. Kalınlık farkı, hacim kaybı, ağırlık kaybı radyoizotop ve iz değişim yöntemleri gibi farklı çalışma esaslarına dayalı yöntemlerle yapılmış çalışmalar bulunmaktadır [17-22]. Çalışmada ise ağırlık ve hacim kaybı yöntemi kullanılmıştır.

\section{BULGULAR}

\subsection{Yoğunluk Değeri}

Yap1 ürünlerinde, gözenekliliğe bağlı olarak etkin 1S1 yalıtımı, hafifletilmiş yap1 elemanlarının oluşturulması ve üretilen yapının hafifliğinin sağlanması, taşıma ve montaj işlemlerinin kolaylığı ile zaman ve işçilikten tasarruf sağlanması açısından mümkün olduğunca düşük yoğunluk aranmaktadır. Ayrıca birim hacim ağırlığı yüksek olan ürünler, ses titreşimlerini atomik yapıda daha iyi ilettiklerinden sönümleme yetenekleri zayıflamaktadır.

Üretilen $\% 50$ baca tozu katk1l kompozit malzemenin yapıda kullanılmasına yönelik, yoğunluk deneyleri yapılmış, deneylerde elde edilen sonuçlar Çizelge 6'da verilmiştir. Kardemir Demir Çelik Fabrikası'ndan alınan baca tozunun 
yoğunluğu $1,998 \mathrm{~g} / \mathrm{ml}$ olarak tespit edilirken, atık LDPE'nin yoğunluğu, genel ticari literatürde belirtildiği gibi $0,92 \mathrm{~g} / \mathrm{ml}$ olarak belirlenmiştir. Üretilen $\% 50$ baca tozu katkılı numunenin yoğunluğu ise bu verilere paralel şekilde gelişmiş ve $1,455 \mathrm{~g} / \mathrm{ml}$ olarak tespit edilmiştir.

Çizelge 6. Yoğunluk değerleri

\begin{tabular}{|l|c|}
\hline Malzemeler & Yoğunluk $(\mathrm{g} / \mathrm{ml})$ \\
\hline Yüksek firın baca tozu & 1,998 \\
\hline Atık polietilen & 0,92 \\
\hline Kompozit malzeme & 1,455 \\
\hline
\end{tabular}

\subsection{Su Emme Oranı}

Yap1 ürünlerinde su emme oranı oldukça önemlidir. Tavan-taban veya yan yüzeylerinden yapı içine giren su, yapı malzemesinin nem içeriği ile ısısının değişmesine neden olmakta, 1sı ve su içeriğindeki değişim de malzemede büzülme ve şişme gibi hacimsel deformasyonlara yol açabilmektedir. Meydana gelen bu hacimsel deformasyonlara bağlı olarak malzemede zamanla mikro çatlaklar oluşabilmekte ve oluşan bu mikro çatlaklardan, yapı malzemesi içerisine suyun girişi ve onun içerisindeki hareketi çok daha kolaylaşabilmektedir [23]. Malzemenin yapı içinde ya da dış cephede kullanılması halinde sudan etkilenmemesi, malzemenin ve kullanıldığg yapının ömrünü uzatacaktır. $\mathrm{Bu}$ nedenle, dış cephede kullanılacak pres ve klinker tuğlalarda, su emme oranının $\% 8$ 'den daha az olması beklenmektedir [24].

Plastik kompozit numunelerin 2. saat, 14., 28. ve 56. günlerdeki su emme oranı ASTM D 570 standardına göre belirlenmiş ve Çizelge 7'de sunulmuştur. Buna göre numunenin su emme oranında zamana bağlı olarak artış olduğu ve atık düşük yoğunluklu polietilene göre 2 . saatte olmasa da 14., 28. ve 56. günlerde daha fazla su emdiği gözlenmiştir (Şekil 5).

Çizelge 7. Su emme oranı (\%)

\begin{tabular}{|l|c|c|c|c|}
\hline & 2. saat & 14. gün & 28. gün & 56. gün \\
\hline Atık LDPE & 0,161 & 0,410 & 1,352 & 2,28 \\
\hline $\begin{array}{l}\text { Kompozit } \\
\text { malzeme }\end{array}$ & 0,105 & 1,107 & 2,670 & 4,27 \\
\hline
\end{tabular}

Elde edilen sonuçlara bağlı olarak, üretilen kompozit numunenin ilk 2 saatte su emme oranı $\% 0,1$ civarında gözlenmiştir. $\mathrm{Bu}$ değer, genel olarak malzemenin oldukça düşük su emme oranına sahip olduğunu göstermektedir. Bu durum, üretilen kompozit malzemenin iç mekanda kullanılabilmesinin yanı sıra dış mekanda da kullanılabileceğini göstermektedir.

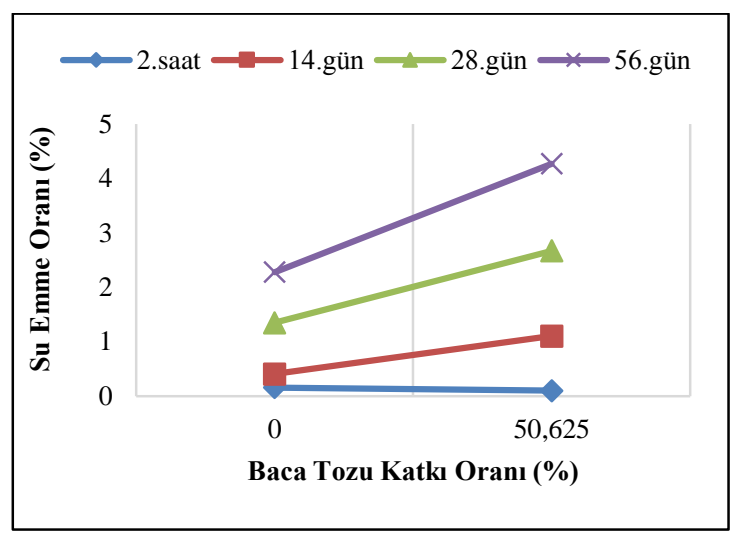

Şekil 5. Atık LDPE ve baca tozu katkılı LDPE'nin zamana bağlı su emme oranı değişimi

\section{3. Çekme Dayanımı}

Bir malzemenin mekanik dayanımı yönünden, hangi yönde ve hangi yük sınırında plastik hale geçeceği veya hangi gerilme değerinde kırılacağını tespit etmek, malzemenin mekanik özelliğinin belirlenmesi ve yapıda kullanım yerine karar verilmesi açısından önemli bir unsurdur. Yapı için tehlikeli sayılabilecek bu sınırların deneylerle saptanması gerekmektedir. Çekme deneyi, malzemelerin ekseni doğrultusunda çekmeye zorlandığı zaman göstermiş olduğu davranışları belirlemek için yapılmaktadır. Bir malzeme ekseni doğrultusunda çekmeye zorlandiğında, boyu uzayıp, kesiti daralmaktadır. Kuvvet uygulanmaya devam edilip plastik deformasyon bölgesine geçildiğinde, malzemedeki bazı değişikliklerden sonra kopma meydana gelmektedir.

Kompozit malzemenin çekme dayanımı bilgisayar yazılımı aracılığıyla deneysel veri toplama yöntemi ile elde edilmiş olup maksimum çekme, 
kopma enerjisi ve elastisite (young) modülü belirlenmiştir. Bu veriler Çizelge 8'de verilmiştir.

Çizelge 8. Çekme deneyi verileri

\begin{tabular}{|c|c|c|c|}
\hline & $\begin{array}{c}\text { Çekme } \\
\text { dayanımı } \\
(\mathrm{MPa})\end{array}$ & $\begin{array}{c}\text { Kopma } \\
\text { enerjisi } \\
(\mathrm{J})\end{array}$ & $\begin{array}{c}\text { Elastisite } \\
\text { modülü } \\
(\mathrm{MPa})\end{array}$ \\
\hline $\begin{array}{c}\text { Atık } \\
\text { LDPE }\end{array}$ & 12,26 & 82,75 & 168,32 \\
\hline $\begin{array}{c}\text { Kompozit } \\
\text { malzeme }\end{array}$ & 11,72 & 11,53 & 626,29 \\
\hline
\end{tabular}

Yüksek katkı oranına bağlı olarak çekme dayanımının ve elastisite modülünün artması beklenen bir durum olup, fakat katkı elemanının partikül şeklinde olması ya da birim kesitte partikül miktarının artması nedeniyle matris yüzdesinin azalması gibi muhtemel nedenlerle mukavemet artışı sağlanmadığı ve birim kesitteki gerilme değerinin düştüğü düşünülmektedir. $\mathrm{Bu}$ durum ayrıca baca tozunun fiziksel yapısına bağlı olarak, numunenin elastikiyet özelliğinin azaldığ anlamına gelmektedir. Bu durumda elyaf takviyeli bir katkı maddesi takviye edilen atık LDPE ile oluşturulan kompozit malzemede durumun değişsebileceği düşünülebilir.

Çekme deneyinden elde edilen veriler kapsamında, baca tozuna bağlı gevrek ve sünek kırılmaya göre, kopma enerjisinin azaldığı gözlenmiştir (Şekil 6 ve 7). $\mathrm{Bu}$ durum baca tozu takviyesiyle LDPE numunenin davranışının süneklikten (Şekil 6) gevrekliğe geçtiğini göstermektedir (Şekil 7). Şekil 7'de \%50 takviyeli kompozit malzemenin çekme deneyi esnasında aynı şartlar altında 7 numune ile gerçekleştirilmesi sonucu elde edilen çekme davranışları görülmektedir.

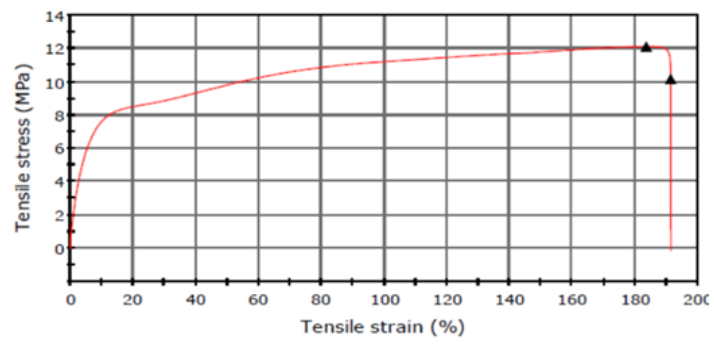

Şekil 6. Atık LDPE'de (katkısız) numunede çekme davranışı

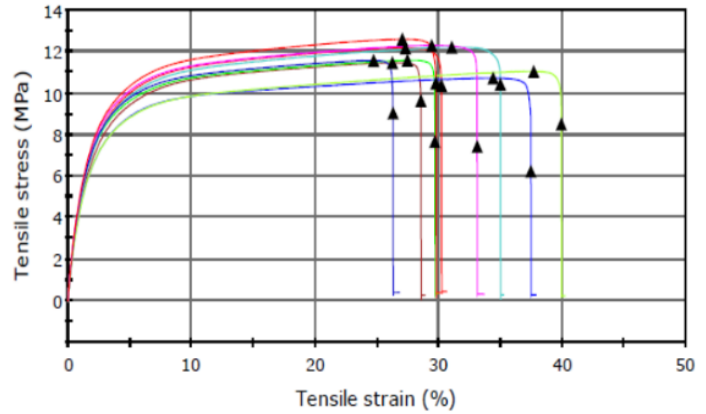

Şekil 7. $\% 50$ baca tozu katkılı numunede çekme davranışı

Üretilen baca tozu katk1lı kompozit malzemenin ve plastik esaslı zemin kaplama malzemelerinin çekme dayanımına yönelik verilen değerler incelendiğinde, kompozit malzemenin elastisite modülü değerinin PVC ve poliüretan esaslı kaplama malzemelerine yakın, epoksiden düşük olduğu çekme dayanımının da diğer plastik esaslı malzemelerden düşük olduğu görülebilmektedir. $\mathrm{Bu}$ durum, kompozit malzemenin matrisini oluşturan LDPE'nin atık olmasından ve rastgele olarak seçilmesinden dolayı beklenen bir sonuçtur. Fakat elde edilen verilerden yola çıkılırsa, yapıda çok fazla mekanik dayanım gerektirmeyecek alanlarda kullanımında bir sıkıntı olmayacağı görülebilmektedir.

\subsection{Aşınma Dayanımı}

Yapı malzemelerinin aşınma davranışlarının bilinmesi, yapıdaki kullanım koşullarından kaynaklanabilecek deformasyonların büyüklüğünün tahmin edilebilmesi konusunda yardımcı olacaktır.

Her malzeme türü, farklı aşınma davranışları göstermektedir. Seramiklerde aşınma mekanizması; büyük çoğunlukla seramik bünyedeki tek tanelerin mekanik ve/veya kimyasal zorlamaların etkisiyle bünyeden ayrılması şeklindedir. Diğer bazı seramiklerde ise aşınma; bir taneden veya yüzeyden mikropartiküllerin kopması sonucu olmaktadır [25].

Polimer esaslı malzemelerde, kayma hızı, uygulanan kuvvet ve sıcaklık ile aşınma miktarı 
önemli oranda değișmektedir [26]. Polimer malzeme ile temas halinde bulunan rijit karşı yüzeyin pürüzlülüğü arttırılırsa pürüzlülüğün belli bir sınır değerden büyük olması durumunda abraziv aşınma etkili olmaya başlamaktadır. Bu sınır değer farklı polimer malzemeler için birçok parametreye bağlı olarak değişmektedir. Polioksimetilen, poliamid 6 , poliamid 66, politetrafloetilen ve yüksek yoğunluklu polietilen gibi malzemelerde yapılan çalışmalar sonucu $0,8 \ldots 1 \mu \mathrm{m}$ maksimum pürüz yüksekliği değerinden sonra abraziv aşınmanın etken olduğu gözlenmektedir [27,28]. Bu nedenle kompozit disk numuneler, aşınma deneyine başlamadan önce, aşınan malzemenin düz ve pürüzsüz bir yüzeye sahip olmasını sağlamak amacıyla, zımparalama/patlatma cihazı ile sirasiyla 0, 100, 240, 400, 600, 1000, 1200 numara SiC zimpara kâğıdına karşı sulu zımparalanarak yüzey pürüzlülüğü giderilmeye çalışılmıştır. Zımparalama işleminin ardından, zımparalanan numunelerin yüzey pürüzlülüğü, pürüzlülük ölçüm cihazı ile tespit edilmiştir. Numunelerde ölçülen pürüzlülük değerinin ortalaması $0,31 \mu \mathrm{m}$ şeklinde tespit edilmiş ve bu değerin pürüzlülük sınır değerini aşmadığından numunelerin aşınma deneyi için uygun olduğuna karar verilmiştir. Ayrıca atık LDPE ve \%50 baca tozu katk1lı numunelerde yapılan yüzey pürüzlülüğü ölçüm sonuçları incelendiğinde baca tozuna bağlı olarak pürüzlülüğün yüksek seyrettiği gözlenmiştir (Çizelge 9). Ayrı süre ve yöntemle zımparalama işlemine tabi tutulan katkılı ve katkısız numunelerden katk1lı numunede yüksek pürüzlülük değerinin zımparala işlemiyle tozun numune yüzeyine çıkması neden olduğu söylenebilmektedir.

Çizelge 9. Yüzey pürüzlülüğü verileri

\begin{tabular}{|c|c|}
\hline Malzemeler & $\begin{array}{c}\text { Yüzey pürüzlülüğü } \\
(\text { Ra- } \mu \mathrm{m})\end{array}$ \\
\hline Atık LDPE & 0,185 \\
\hline Kompozit malzeme & 0,314 \\
\hline
\end{tabular}

Çizelge 10'da görüldüğü gibi, $450 \mathrm{~m}$ yol için, atık LDPE (\%0 katkı) ve \%50 katkı oranlarına bağlı olarak hacim kaybı değerlerinin sırasıyla 1,357; $0,492 \mu \mathrm{m}^{3}$ olduğu tespit edilmiştir. $\mathrm{Bu}$ durum
$900 \mathrm{~m}$ yol için, sırasıyla 2,962; $1,076 \mu \mathrm{m}^{3}$ şeklindedir. Hacimsel kayıp, baca tozu katkı oranına bağlı olarak azalmaktadır. Bunun nedeni, numunede bulunan baca tozu katkısina paralel, sertliğin artması ve aşınma değerinin azalması olarak yorumlanabilmektedir. Ayrıca, numunede baca tozuna bağlı olarak, baca tozunun aşındırılan yüzeyde kayma etkisi yapabilmesi de diğer nedenlerden biri olarak söylenebilmektedir.

Çizelge 10. Aşınma verileri

\begin{tabular}{|c|c|c|c|c|c|c|}
\hline & \multirow{2}{*}{$\begin{array}{c}\text { Sürt. } \\
\text { kats. } \\
\end{array}$} & $\begin{array}{c}\text { Sürt. } \\
\text { kats. }(\mu) \\
\end{array}$ & $\begin{array}{c}\text { Alansal kayıp } \\
\left(\mu \mathrm{m}^{2}\right)\end{array}$ & \multicolumn{2}{|c|}{$\begin{array}{c}\text { Hacimsel kayıp } \\
\left(\mu \mathrm{m}^{3}\right)\end{array}$} \\
\hline $\begin{array}{c}\text { Atık } \\
\text { LDPE }\end{array}$ & 0,05 & 0,04 & $350 \mathrm{~m}$ & $900 \mathrm{~m}$ & $450 \mathrm{~m}$ & $900 \mathrm{~m}$ \\
\hline $\begin{array}{c}\text { Komp. } \\
\text { Malz. }\end{array}$ & 0,04 & 0,02 & 1295 & 2832 & 0,492 & 1,076 \\
\hline
\end{tabular}

Sonuçlar incelendiğinde gözlenen aşınma kayıplarının çok düşük değerlerde olması nedeniyle, üretilen kompozit malzemenin yap1 zemininde kullanımına uygun olduğu söylenebilmektedir.

\section{SONUÇ}

Çalışmada yüksek üretim enerjisine sahip, ithal girdisi yüksek olan plastik ve demir çelik endüstrilerinin üretim ve kullanım sonrası atıklarından yüksek fırın baca tozu ve LDPE, oluşum enerjisi düşük, geri kazanılmış malzeme içeren ve geri dönüştürülebilir bir yapı malzemesi hedefiyle bir araya getirilmiş ve elde edilen kompozit malzemenin yapıda kullanılabilirliği saptanmıştır. Isıl işlem kullanılarak \%50-\%50 oranla bir araya getirilen kompozit malzemenin yoğunluğu, su emme oranı, çekme dayanımı ve aşınma oranları yapılan test ve deneylerle belirlenmiştir. $\mathrm{Bu}$ deneyler sonucunda, yoğunluğu $1,455 \mathrm{~g} / \mathrm{ml}$ olarak tespit edilen $\% 50$ oranında baca tozu katkılı kompozit malzemenin ilk 2 saatte su emme oranı \%0,1 civarında gözlenmiştir. Bu değer, genel olarak malzemenin oldukça düşük su emme oranına sahip olduğunu göstermiş olup, üretilen kompozit malzemenin iç mekânda kullanılabilmesinin yanı sıra diş mekanda da kullanılabileceğini doğrulamaktadır. Kompozit malzemenin matrisini oluşturan LDPE'nin rastgele seçilmesinden dolayı düşük çekme dayanımına 
$(11,72 \mathrm{MPa})$ sahip olduğu ve yapıda çekme dayanımına maruz yerlerde taşıyıcı olarak kullanılamayacağı, buna karşın diğer dayanım gerektiren durumlarda yeterli özelliklere sahip olduğu saptanmıştır. Servis ömrüne ilişkin tespitin yapılmadığı bu çalışmada, malzemenin aşınma dayanımının kabul edilebilir değerlerin üzerinde olması ve aşınma kayıplarının düşük değerde saptanması nedeniyle özellikle zemin kaplaması olarak kullanımına çok uygun olduğu görülmüştür.

Bu çalışmada, çevreyi olumsuz etkileyen iki farklı atık ürünün bir araya getirilmesiyle çevre kirliliğinin azaltılması hedefi sağlanmıştır. $\mathrm{Bu}$ amaçla üretilmiş, geri kazanılmış malzemenin yapıda kullanımının yanı sıra, çevresel etki göstergeleri karşısındaki niteliklerinin de belirlenmesi çok büyük önem taşımaktadır. Bu bağlamda, üretiminde kullanılan oluşum enerjisinin saptanması, ayrica yeniden geri kazanılabilmesi durumundaki özelliklerinin araştırılması, üretilen bu malzemenin çevre dostu yaklaşımlı projelerde tercih edilerek kullanılabileceğini göstermektedir.

\section{TEŞEKKÜR}

$\mathrm{Bu}$ çalışma Gazi Üniversitesi BAP birimi tarafından 48/2013-01 kodlu bilimsel araştırma proje fonu ile desteklenmiştir.

Baca tozu temininde yardımlarını esirgemeyen Karabük Kardemir A.Ş. Yüksek Fırınlar Müdürü Ahmet AYCAN'a ve her türlü bilgi desteğini sunan Yüksek Fırınlar İşletme Mühendisi Gökhan DOĞANTEPE'ye teşekkür ederiz.

\section{KAYNAKLAR}

1. Robinson, R., 2008. Studies Low Temperature Self Reduction of By-products from Integrated from and Steel Making, Ph. D. Thesis, Lulea University of Technology, Department of Chemical Engineering and Geosciences, Division of Process Metallurgy, Lulea, Sweden, 1-46.

2. Doğantepe, G., 2014. Hematit Karakterli Demir Cevherinden ve Yüksek Fırın Baca
Tozundan Sünger Demir Üretilebilirliğinin Araştırılması, Yüksek Lisans Tezi, Karabük Üniversitesi Fen Bilimleri Enstitüsü, Karabük, Türkiye, 34-35.

3. Fleischanderl, A., Joseph, P., Gebert, W., 1999. Aspect of Recycling of Steelworks Byproducts Through the BOF, SEAISI Q., 28 April, (2) 51-60.

4. Kardemir Demir Çelik Fabrikası A. Aycan ile yapılan sözlü görüşme, 2015.

5. Nyirenda, R.L., 1991. The Processing of Steelmaking Flue Dust: a Review, Proceedings of the First International Conference-Minerals Engineering '91, Singapore, 1003-1025.

6. Tuna Kayılı, M. 2016. Yüksek Fırın Baca Tozu ve Atık Polietilen Kullanılarak Üretilen Kompozit Malzemenin Yapıda Kullanılabilirliğinin Saptanması, Doktora Tezi, Gazi Üniversitesi Fen bilimleri Enstitüsü, Ankara, Türkiye

7. PETKIM Faaliyet Raporu. http://www.webcitation.org/query?url=http $\% 3$

A\%2F\%2Fwww.petkim.com.tr\%2FSayfa\%2F1 $\% 2$ F $176 \% 2$ FYATIRIMCI-ILISKILERI-

OPERASYONEL-VEFINANSAL-VERILERFAALIYETRAPORLARI.aspx $+\&$ date $=2016$ 05-05 Tarih: 05.05.2014

8. https://ekonomi.isbank.com.tr/UserFiles/pdf/sr 201703_demircelik.pdf Tarih: 13.06.2017.

9. T.C. Bilim, Sanayi ve Teknoloji Bakanlığı, Demir Çelik Sektörü Raporu, 2012/1.

10. ECE Steel Series, ECE/Steel/68, 1990. The Recuperation and Economic Utilization of Byproducts of Iron and Steel Industry, United Nations Economic Commisionfor Europe, 2741, 60-78.

11. ISIJ Committee on Enviromental Affairs, 1987. The Manegment of Steel Industry By-Product and Wastes, Brussel.

12. Özkan, V., 2013. Yüksek Fırın ve Sinter Müdürlüğü Atık Raporu, Yüksek Fırınlar ve Sinter Müdürlüğü, Kardemir A.Ş, Karabük, 1-3.

13. PLASFED, 2014. Demirci Plastik Sanayicileri Federasyonu, Türkiye Plastik Sektör İzleme Raporu.

14. PAGEV http://www.webcitation.org/query?url=http\%3 A\%2F\%2Fwww.pagev.org.tr\%2Fcontents_TR. 
asp $\% 3$ Fid $\% 3 D 12 \% 26$ pid $\% 3 D 351+\&$ date $=201$ 6-05-05, Tarih: 15.09.2015.

15. ASTM D 792-13, 2013. Standard Test Methods for Density and Specific Gravity (Relative Density) of Plastics by Displacement, American Society for Testing and Materials.

16. ASTM D 570-10, 2010. Standard Test Method for Water Absorption of Plastics, American Society for Testing and Materials.

17. Koç, R., 2011. Mühendislik Plastiklerinin Aşınma Davranışlarının Deneysel İncelenmesi, Makine Teknolojileri Elektronik Dergisi, 8(2), 27-40.

18. Panin, S.V., Kornienko, L.A., Sondghaitam, N., Ivanova, L.R., Shil'ko, S.V., 2012. Abrasive Wear of Micro-and Nanocomposites Based on Super-high-molecular Polyethylene (SHMPE). Part 1. Composites based on shmpe filled with microparticles $\mathrm{AlO}(\mathrm{OH})$ and $\mathrm{Al}_{2} \mathrm{O}_{3}$. Journal of Friction and Wear, 33(5), 381-387.

19. Sugözü, İ., Mutlu, İ., 2008. Fren Balata Malzemelerinin Sürtünme ve Aşınmaya Etkisinin İncelenmesi. Makine Teknolojileri Elektronik Dergisi, 4, 33-40.

20. Suresha, B., Chandramohan, G., Jawahar, M.A., Mohanraj, S. 2008. Three-body Abrasive Wear Behavior of Filled Epoxy Composite Systems, Journal of Reinforced Plastics and Composites. 00(0), 1-10.

21. Rajesh, J.J., Bijwe, J., 2006 . Statistical Analysis of Abrasive Wear Data of Aramid Fabric-reinforced Polyethersulfone Composites, Journal of Reinforced Plastics and Composites, 25(9), 1013-1022.

22. Tiwari, S., Bijwe, J., 2013. Influence of Fibermatrix Interface on Abrasive Wear Performance of Polymer Composites. Journal of Reinforced Plastics and Composites, 0(00), $1-12$.

23. Özdemir, A., 2002. Bazı Yapı Malzemelerin Kapiler Su Emme Potansiyelleri, Jeoloji Mühendisliği, 261, 19.

24. Çiçek, Y.E., 2015. Pişmiş Toprak Tuğla, Bimsbeton, Gazbeton ve Perlitli Yap1 Malzemelerinin Fiziksel, Kimyasal ve Mekanik Özelliklerinin Karşılaştırmalı Olarak İncelenmesi. Doktora Tezi, İstanbul Teknik
Üniversitesi Fen Bilimleri Enstitüsü, s. 112, İstanbul.

25. Başman, G., Atar, E., Kayalı, S., 2001. Seramik Malzemelerin Aşınma Davranışı. Metalurji, 127, 39.

26. Glease, W.A., 1995. Friction and Wear of Ceramics, ASM Handbook, 18, 812-815.

27. Czichos, H., 1983. Influence of Adhesive and Abrasive Mechnisms on the Tribological Behavior of Thermoplastic Polymers, Wear, 88, 27-43.

28. Clarke, C.G., Allen, C., 1991. The Water Lubricated, Sliding Wear Behaviour of Polymeric Materials Against Steel, Tribology International, 24, 109-118. 
